\title{
Carbamazepine Removal from Aqueous Solution by Green Synthesis Zero-Valent Iron/Cu Nanoparticles with Ficus Benjamina Leaves' Extract
}

\author{
Hossam Mohammed Abdel-Aziz ${ }^{1}\left[\right.$ ] Rabie Saad Farag ${ }^{2} \cdot$ Soha Ali Abdel-Gawad ${ }^{3}$ \\ Received: 23 April 2019 / Revised: 13 July 2019 / Accepted: 20 July 2019 / Published online: 1 August 2019 \\ (C) The Author(s) 2019
}

\begin{abstract}
Green synthesis of nanoparticles is an eco-friendly treatment technique. Bimetallic nano zero-valent $\mathrm{Fe} / \mathrm{Cu}$ was successfully prepared by green synthesis by Ficus Benjamina leaves (FB-ZVI/Cu). The nanoscale FB-ZVI/Cu was characterized by scanning electron microscope, Fourier transform infrared spectroscopy, and dispersive X-ray spectroscopy. The characterization revealed that synthesis and presence of iron-copper nanoparticles and biomolecules which could help in capping the bimetallic nanoparticles. Subsequently, nanoscale zero-valent $\mathrm{Fe} / \mathrm{Cu}$ particles were used to remove carbamazepine from the aqueous medium under varying experimental conditions, including $\mathrm{pH}$, initial carbamazepine concentration, $\mathrm{Fe} / \mathrm{CuNPs}$ dose, stirring rate, and contact time. The removal efficiency of carbamazepine reached $95 \%$ under the condition of dose $0.4 \mathrm{~g} \mathrm{~L}^{-1}$, time $20 \mathrm{~min}$, and $\mathrm{pH}$ 5. The results were analyzed according to the Freundlich and Langmuir adsorption isotherms. The adsorption data are more appropriate by the Langmuir adsorption model $\left(R^{2}=0.998\right)$ with $q_{\max }=26.15 \mathrm{mg} \mathrm{g}^{-1}$. Overall, $\mathrm{FB}-\mathrm{nZVFe} / \mathrm{Cu}$ is a promising green substance to remove carbamazepine from aqueous solutions. The effect of different operating parameters was investigated using linear regression analysis, they were found to account for more than $97 \%$ of the variables affecting the removal process.
\end{abstract}

\section{Article Highlights}

- Bimetallic nZVFe/Cu was synthesized using the Ficus Benjamina leaves' extracts.

- Nanoparticles were characterized by SEM, EDAX, and FTIR.

- The green-synthesized FB-nZVFe/Cu nanoparticles can remove carbamazepine from aqueous solutions.

- Removing mechanism based on adsorption and reduction is proposed.

- A high removal percentage of carbamazepine was $95 \%$.

- Lower FB-nZVI/Cu PZC values.

Keywords Carbamazepine $\cdot$ Bimetallic $\cdot \mathrm{nZVI} / \mathrm{Cu} \cdot$ Ficus Benjamina $\cdot$ Green synthesis

Hossam Mohammed Abdel-Aziz

hossam_elywa@yahoo.com

1 Chemical Industries Development (CID) Company, Giza, Egypt

2 Chemistry Department, Faculty of Science, Al-Azhar University, Cairo, Egypt

3 Chemistry Department, Faculty of Science, Cairo University, Giza, Egypt

\section{Introduction}

Carbamazepine (CBZ) is an antiepileptic drug and one of the most persistent pharmaceuticals in the ecosystem. This drug had been found in various surface water, at a concentration more than other pharmaceutical drugs (Gurung et al. 2018; Li et al. 2015; Yang et al. 2016; Baghdadi et al. 2016; Liu et al. 2018). CBZ could endure intact after 8-10 years without exposure to adsorption or to degradation due to its high resistance to photodegradation and biodegradation (Samara et al. 2016; Gurung et al. 2018; 
Rajendran and Sen 2018). Annual global consumption of CBZ is more than 1000 tons and about $28 \%$ of it is finished at wastewater treatment plants as unmetabolized forms (Gurung et al. 2018; Domínguez et al. 2010; GarcíaGómez et al. 2014). CBZ causes several harmful effects; therefore, it is necessary to remove these contaminants from industrial wastewater prior to discharge in wastewater (Cunningham et al. 2010; Li et al. 2015; Nielsen et al. 2015). The removal of CBZ via different techniques, such as sedimentation, rapid sand filtration, chemical precipitation, metal salt coagulation, and reverse osmosis, is limited (Baghdadi et al. 2016; Chtourou et al. 2018; Liu et al. 2018).

Many researchers have focused on developing new methods using nano-catalysts technology to overcome these limitations (Mahmoud et al. 2018b; Abdel-Gawad et al. 2016; Farag et al. 2018a, b). Since the 1990s, iron nanoparticles (FeNPs) have been used to treat water because of its characteristics viz. high surface area, wide dispersion of reactive surface sites, and unique adsorption (Mahmoud et al. 2018a, 2019b, Mostafa et al.). Copper nanoparticles (CuNPs) have significant chemical and physical properties, less cost, and high surface area (Khani et al. 2018; Fathima et al. 2018). CuNPs is the highest stable in comparison with these zerovalent metals (Zhang et al. 2017; Wu et al. 2009). FeNPs and CuNPs play a crucial role in the removal of various contaminants from the aquatic environment. Nowadays, most of the nanoparticles are prepared by sodium borohydride, but they are classified from the monocrystals that cause significant contamination if used extensively. It is, therefore, necessary to find alternative, low-cost, environmentally friendly methods (Zhu et al. 2018; Danish et al. 2017). Traditional methods adopted for the synthesis of FeNPs or CuNPs by sonochemical synthesis, vacuum sputtering, physical method (attrition), and thermal decomposition. These methods have many limitations viz. high temperature and pressure or energy requirement, so they are relatively expensive (Devatha et al. 2016; Danish et al. 2017).

Green synthesis has become one of the most important low-cost and environmentally friendly alternative methods for synthesizing nanoparticles through using plant leaf extract, which contains a large amount of both reducing and capping agents via. polyphenols, flavonoids, and other reducing substances, which is capable of reducing iron and copper salts to zerovalent and protecting them from agglomeration (Devatha et al. 2016; Farag et al. 2018a, b). Ficus Benjamina leaves' extract provides a greener, economic, and fast method for the synthesis of nanoparticles with an appropriate size (Puente et al. 2019; Al-Qahtani 2017). So far, copper and $\mathrm{Fe}$ nanoparticles prepared by green synthesis have proven to be efficient to remove many contaminants (Zhu et al. 2018; Danish et al. 2017). Although studies have demonstrated the feasibility of the green synthesis of nZVI, the application of green synthetic iron-copper bimetallic nanoparticles has rarely been reported. Several studies have shown that the bimetallic nanoparticles are more efficient than monometallic NPs (Qin et al. 2016; Sepúlveda et al. 2018; Mahmoud et al. 2019a). We have not known any research related to the green-synthesized bimetallic nanoparticles for removing carbamazepine in industrial wastewater.

The objective of this study is to evaluate the capacity of green synthetic nanoscale zero-valent iron/Cu was prepared by Ficus Benjamina leaves (FB-nZVI/Cu) and applied to remediate carbamazepine from aqueous solutions. The $\mathrm{Fb}-\mathrm{nZVI} / \mathrm{Cu}$ was characterized using a scanning electron microscope (SEM), Fourier transform infrared spectroscopy (FTIR), and energy-dispersive X-ray analysis (EDAX). The effect of the operating parameter was studied using different operating parameters (e.g., contact time, $\mathrm{pH}$, concentrations, adsorbent dose, and stirring rate). In supplement, the Freundlich, Langmuir isotherms are used to fit the data.

\section{Experimental}

\section{Chemicals and Reagents}

All chemicals used were of the analytical reagent grade and of the highest purity; such as ferrous sulfate dihydrate ( $\mathrm{FeSO}_{4} \cdot 2 \mathrm{H}_{2} \mathrm{O}$, ADWIC Co. Ltd.), copper sulfate pentahydrate $\left(\mathrm{CuSO}_{4} \cdot 5 \mathrm{H}_{2} \mathrm{O}\right.$, ADWIC Co. Ltd.), Ficus Benjamina leaves (Ficus tree, Egypt.), carbamazepine $\left(\mathrm{C}_{15} \mathrm{H}_{12} \mathrm{~N}_{2} \mathrm{O}\right.$, Zhejiang Jiuzhou Pharmaceutical Co., Ltd.), anhydrous alcohol (Fisher Scientific Co. Ltd.), and anhydrous methanol (Fisher Scientific Co. Ltd.). The change of $\mathrm{pH}$ was adjusted using $0.1 \mathrm{M} \mathrm{NaOH}$ and $0.1 \mathrm{M} \mathrm{HCl}$ solutions.

\section{Methods}

\section{Ficus Benjamina Leaves' Extract}

Ficus Benjamina leaves (FB) were washed with Tap water to remove dust, then with distilled water and dried in oven at $50{ }^{\circ} \mathrm{C}$. Then, the leaves were cut into small pieces and sieved using a $2.5 \mathrm{~mm}$ sieve. In Erlenmeyer flask, $20 \mathrm{~g}$ of leaves was added to $100 \mathrm{~mL}$ distilled water and boil the solution at $60{ }^{\circ} \mathrm{C}$ for $5 \mathrm{~min}$ followed by filtrating using Whatman no. 1 filter paper, and the filtrate will be stored at $4{ }^{\circ} \mathrm{C}$ until used as a capping and reducing agent.

\section{Synthesis of $\mathrm{Fb}-\mathrm{nZVI} / \mathrm{Cu}$}

$\mathrm{Fe}$ (II) and $\mathrm{Cu}$ (II) mixed solution was prepared by dissolving solid $0.94 \mathrm{~g} \mathrm{FeSO} 4 \cdot 2 \mathrm{H}_{2} \mathrm{O}$ and $0.18 \mathrm{~g} \mathrm{CuSO}_{4} \cdot 5 \mathrm{H}_{2} \mathrm{O}$ in $100 \mathrm{~mL}$ of distilled water. For synthesis $\mathrm{Fb}-\mathrm{nZVI} / \mathrm{Cu}$ nanoparticles' process, $50 \mathrm{~mL}$ of Ficus Benjamina leaves' extract 
(FBLE) was taken and added to $100 \mathrm{~mL}$ of $\mathrm{Fe}$ (II)-Cu(II) mixture drop by drop, followed stirred for $20 \mathrm{~min}$ to form the nanoparticles. The color of the solution was changed from yellowish to brown then black, and this was showed the formation of FB-nZVI/Cu nanoparticles. The FB-nZVI/Cu nanoparticles were separated using centrifugation for $10 \mathrm{~min}$ and the resulting $\mathrm{FB}-\mathrm{nZVI} / \mathrm{Cu}$ was washed with distilled water and with anhydrous alcohol. The FB-nZVI/Cu was then placed at $65^{\circ} \mathrm{C}$ in a vacuum dryer oven, and then was stored at $4{ }^{\circ} \mathrm{C}$ until used (Zhu et al. 2018).

\section{Characterization of FB-nZVI/Cu}

The prepared FB-nZVI/Cu sample was analyzed using Scanning electron microscope (SEM), EDAX, and FTIR spectroscopy. Before field-emission scanning electron microscopy FB-nZVI/Cu nanoparticles were coated by gold which increases electron scatter to give high contrast before definition the morphology and measuring the particle size. EDAX is an analytical technique used to determine the composition of the sample. FT-IR spectroscopy is necessary to prove the formation of nanoparticles. It helps in identifying the chemical composition of prepared FB-nZVI/Cu nanoparticles.

\section{Point of Zero Charge}

Dissolve $7.46 \mathrm{~g}$ of $\mathrm{KCL}$ in $1000 \mathrm{~mL} \mathrm{H}_{2} \mathrm{O}$. Take $20 \mathrm{~mL}$ of $0.1 \mathrm{M} \mathrm{KCl}$ solution in a series of $100 \mathrm{~mL}$ Erlenmeyer flasks and the initial $\mathrm{pH}$ was adjusted to $2,4,6,8,10$, and 12 by adding $0.5 \mathrm{~N} \mathrm{NaOH}$ or $0.5 \mathrm{~N} \mathrm{HCl}$ (pHi). To each flask was added, $10 \mathrm{mg}$ of $\mathrm{FB}-\mathrm{Fe} / \mathrm{Cu}$ nanoparticles and the samples were left for $24 \mathrm{~h}$ at room Temp. Then, the final $\mathrm{pH}$ of each suspension was measured ( $\mathrm{pHf}$ ). The point of zero charge was calculated by plotting $\Delta \mathrm{pH}$ (final $\mathrm{pH}$ - initial $\mathrm{pHi}$ ) vs initial $\mathrm{pH}$ value ( $\mathrm{pHi})$.

\section{Batch Adsorption Studies}

The stock solution containing $1000 \mathrm{mg} \mathrm{L}^{-1}$ of carbamazepine was prepared by dissolving $100 \mathrm{mg}$ of carbamazepine in $100 \mathrm{~mL}$ methanol then diluted to $1000 \mathrm{~mL}$ with distilled water, and the desired solutions were prepared by dilution of the stock solution. The removal process was carried out by mixing that $0.2 \mathrm{~g} \mathrm{~L}^{-1}$ of $\mathrm{Fb}-\mathrm{nZVI} / \mathrm{Cu}$ nanoparticles was added to carbamazepine solution with different concentrations $\left(1,3,5\right.$, and $\left.7 \mathrm{mg} \mathrm{L}^{-1}\right)$. Using different operating parameters, effect of $\mathrm{pH}$, contact time, dose, stirring rate, and concentrations stirring rate was mixed with carbamazepine solution. The removal percentages were calculated using the following equation (SaryEl-deen et al.; El-Shafei et al. 2016):

Sorption $[\%]=\left[C_{0}-C_{\mathrm{e}}\right] / C_{0} \times 100$, where $C_{0}$ is the initial concentration $\left(\mathrm{mg} \mathrm{L}^{-1}\right)$ of carbamazepine in solution and $C_{\mathrm{e}}$ is the equilibrium concentration $\left(\mathrm{mg} \mathrm{L}^{-1}\right)$ of carbamazepine in solution. The amount of carbamazepine removed by $\mathrm{FB}-\mathrm{nZVI} / \mathrm{Cu}$ nanoparticles was calculated using the following equation:

$q_{\mathrm{e}}[\mathrm{mg} / \mathrm{g}]=\left[\left[C_{0}-C_{\mathrm{e}}\right] V\right] / m$,

where $q_{\mathrm{e}}$ is the equilibrium adsorption capacity $\left(\mathrm{mg} \mathrm{g}^{-1}\right)$, $V$ is the volume of aqueous solution (L), and $m$ is the weight of the adsorbent $(\mathrm{g})$.

\section{Adsorption Study}

\section{Freundlich Isotherm}

The Freundlich isotherm is an empirical equation employed for describing heterogeneous adsorption surface (Freundlich 1906; Abdel-Gawad and Abd El-Aziz 2019a, b) and is given by

$\operatorname{Ln} q_{\mathrm{e}}=1 / n \ln C_{\mathrm{e}}+\ln K_{\mathrm{f}}$,

where $n$ (dimensionless) and $K_{\mathrm{f}}\left(\left(\mathrm{mg} \mathrm{g}^{-1}\right)\left(\mathrm{mg} \mathrm{L}^{-1}\right)^{-1 / n}\right)$ are Freundlich constant related to the adsorption intensity and adsorption capacity, respectively. $\left(K_{\mathrm{f}}\right)$ and $(n)$ evaluated by plotting $\ln q_{\mathrm{e}}$ and $\ln C_{\mathrm{e}}$.

\section{Langmuir Isotherm}

Langmuir isotherm supposes monolayer coverage of adsorbate over a homogeneous surface of adsorbent (Langmuir 1918; Abdel-Gawad and Abd El-Aziz 2019a, b). The Langmuir linearized is given by the following equation:

$C_{\mathrm{e}} / q_{\mathrm{e}}=1 /\left(K_{\mathrm{L}} q_{\max }\right)+C_{\mathrm{e}} / q_{\max }$,

where $q_{\mathrm{e}}\left(\mathrm{mg} \mathrm{g}^{-1}\right)$ is the mass of carbamazepine adsorbed per mass of adsorbent used, $C_{\mathrm{e}}\left(\mathrm{mg} \mathrm{L}^{-1}\right)$ is equilibrium concentration of carbamazepine, $q_{\max }\left(\mathrm{mg} \mathrm{g}^{-1}\right)$ is the maximum monolayer capacity of adsorption, and $K_{\mathrm{L}}\left(\mathrm{L} \mathrm{mg}^{-1}\right)$ is the Langmuir constant related to binding sites affinity and adsorption energy. The plot of $C_{\mathrm{e}} / q_{\mathrm{e}}$ vs $C_{\mathrm{e}}$ employed to generate the values of $q_{\max }$ and $K_{\mathrm{L}}$.

\section{Results and Discussion}

\section{Characterization and Analysis of FB-nZVI/Cu}

\section{Scanning Electron Microscopy (SEM) and EDAX}

Figure 1 shows the image of SEM of a semi-spherical shape FB-nZVI/Cu particles, and the size of these particles ranges around 19-63 $\mathrm{nm}$. The SEM image shows formed large nano-clusters as a result of the magnetic forces between the 


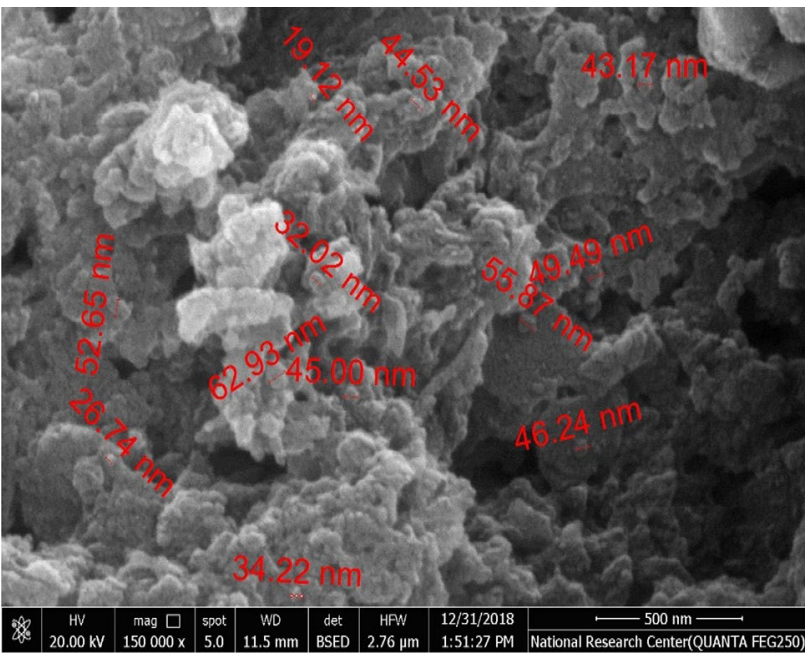

Fig. 1 SEM of prepared FB-nZVI/Cu sample
FB-nZVI/Cu nanoparticles, and also may be due to the centrifugation process for the sample. There are many pores that allow the carbamazepine to be transported better and the spread of contamination mass to the inner FB-nZVI/Cu nanoparticles.

Figure 2 shows EDAX analysis of gold-coated FB-nZVI/ $\mathrm{Cu}$ nanoparticles. $\mathrm{Fe}$ and $\mathrm{Cu}$ peaks indicate the formation of nanoparticles. Other beaks via $\mathrm{C}, \mathrm{O}, \mathrm{Si}$, and $\mathrm{S}$ of leaves extract (Dong et al. 2017, Selvan et al. 2018).

\section{FTIR Measurements}

Figure 3 shows the FTIR spectrum of GT-nZVI/Cu before the reaction in the range of $400-4000 \mathrm{~cm}^{-1}$. The broadband at $3400-3000 \mathrm{~cm}^{-1}$ was attributed to $\mathrm{O}-\mathrm{H}$-stretching vibration and indicates the presence of polyphenols which can improve material stability (Soliemanzadeh and Fekri 2017; Al-Qahtani 2017). The band at $1615 \mathrm{~cm}^{-1}$ was attributed to the stretching vibration of $\mathrm{C}=\mathrm{O}$ ( $\mathrm{Zhu}$ et al. 2018); the peak at $1539 \mathrm{~cm}^{-1}$ indicates the presence of Ficus amide(AlQahtani, 2017); the peak $1362 \mathrm{~cm}^{-1}$ indicates the presence of polyphenols aromatic ring $\mathrm{C}=\mathrm{C}$ stretching vibration (Fathima et al. 2018); and the peak $1102 \mathrm{~cm}^{-1}$ indicates
Fig. 2 EDAX of prepared FBnZVI/Cu sample

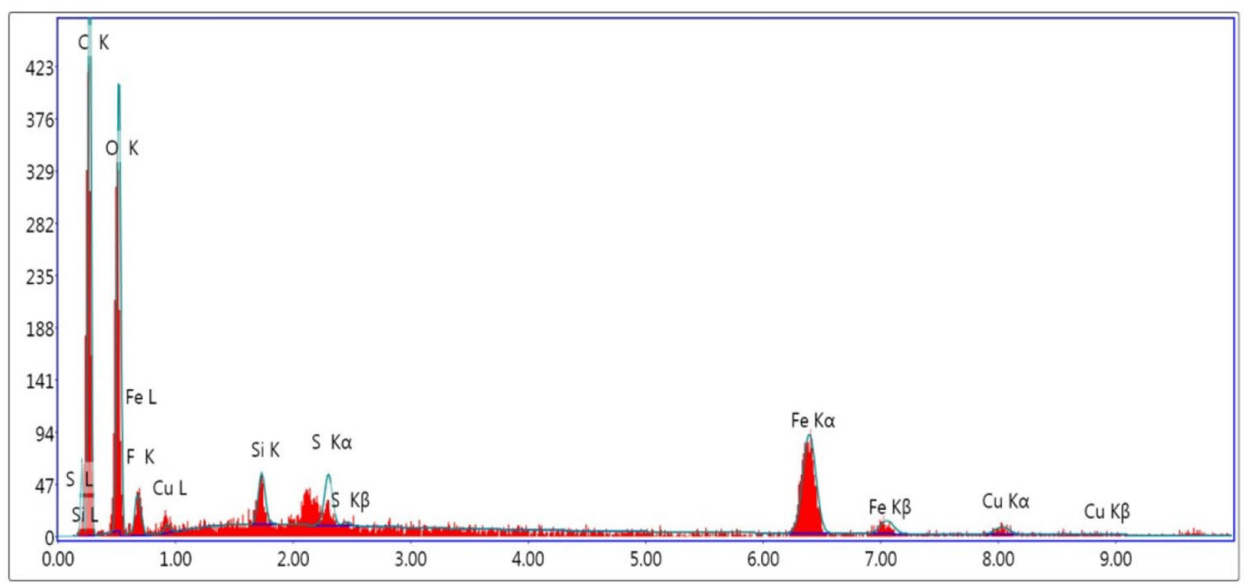

Lsec: 30.00 Cnts 0.000 keV Det: Octane Pro Det Reso

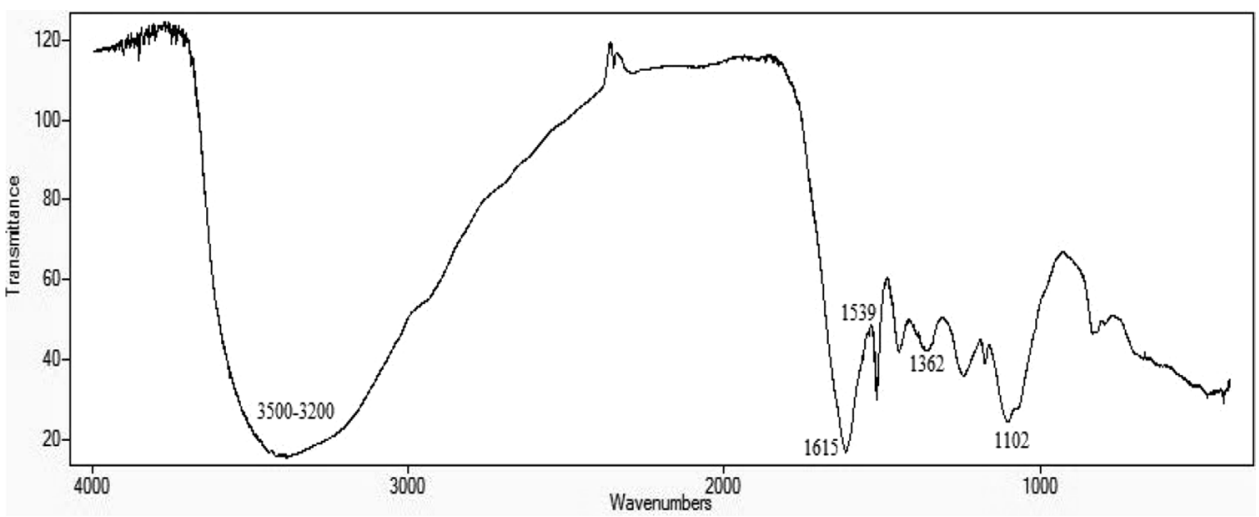


the presence of $\mathrm{C}-\mathrm{O}-\mathrm{C}$ symmetric stretching vibration (Zhu et al. 2018). According to Fig. 3, the presence and intensity of phenolic compounds peaks can reduce $\mathrm{Fe} / \mathrm{Cu}$, and is a strong indicator for FB-nZVFe/Cu synthesized.

\section{Point of Zero Charge (pzc)}

Lower FB-nZVI/Cu point of zero charge (pzc) values can be explained as a result of the high acidity of leaf extracts which were about 4.85 for Ficus Benjamina, as shown in Fig. 4.

\section{Effect of Operating Parameters}

\section{Effect of $\mathrm{pH}$}

Effect of $\mathrm{pH}$ is a significant influence for controlling the adsorption process; $\mathrm{pH}$ solution controls both the adsorbent surface capacity and charge; and charge of contaminant species in medium. Figure 5 shows the removal efficiency of carbamazepine at different values of $\mathrm{pH}(3,5,7$, and 9) at different times $(10,20$, and $30 \mathrm{~min})$, respectively, when the dosage of FB-nZVI/Cu $0.2 \mathrm{~g} \mathrm{~L}^{-1}$, concentration $5 \mathrm{mg} \mathrm{L}^{-1}$, and stirring rate $100 \mathrm{rpm}$ at room temp. The removal efficiency of carbamazepine by FB-nZVI/Cu was $(28,51,45$, and $15 \%),(29,56,47$, and $16 \%)$, and (30, 58, 48, and $17 \%)$, respectively. It was observed that the optimum $\mathrm{pH}$ for the removal was 5. At $\mathrm{pH}>\mathrm{pHpzc}$, the surface of $\mathrm{FB}-\mathrm{nZVI} / \mathrm{Cu}$ was negatively charged, whereas for $\mathrm{pH}<\mathrm{pHpzc}$, the surface of FB-nZVI/Cu was positively charged. In contrast, since carbamazepine is neutral in the range of $\mathrm{pH} 3-10$ (To et al. 2017). At $\mathrm{pH} 3$, low removal efficiency due to the presence of $\mathrm{H}^{+}$ions that occupy available vacant sites, which interfere with the FB-nZVFe/Cu particles (Misra et al. 2018). At pH

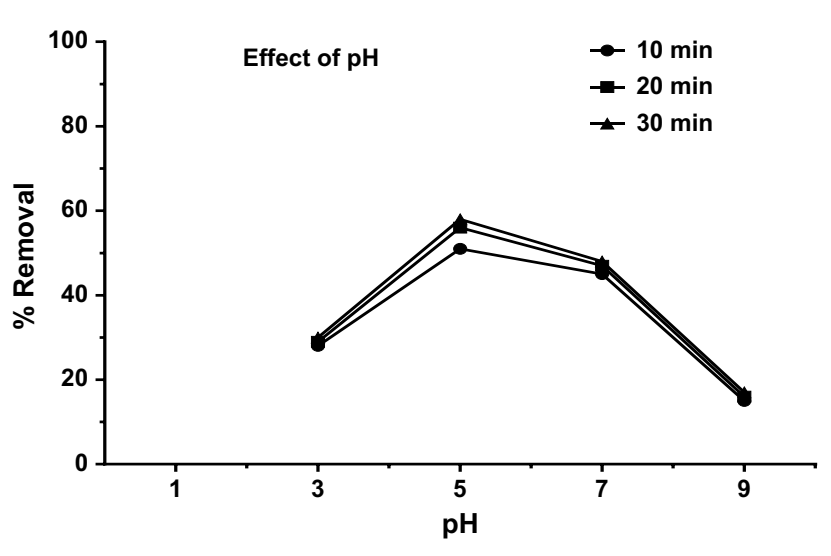

Fig. 5 Effect of $\mathrm{pH}$ on carbamazepine removal

9, the removal efficiency was very low, due to the repulsion, and occurs between $\mathrm{OH}^{-}$ions and negative charged surface of nanoscale particles, thus leading to steric hindrance and weak interaction (Misra et al. 2018; Shan et al. 2016), or may be the low availability of nanoparticles (Misra et al. 2018). Based on the above, pHpzc is the optimum removal of carbamazepine. This was consistent with the results of Gurung et al. (2018), Liu et al. (2018), Zhu et al. (2017) and Yang et al. (2016).

\section{Effect of Contact Time}

The contact time is another important operational parameter effect removal efficiency. The effect on carbamazepine removal studied at different times $(10,20,30,45,60$, and $90 \mathrm{~min}$ ) using $0.2 \mathrm{~g} \mathrm{~L}^{-1}$ of $\mathrm{FB}-\mathrm{nZVI} / \mathrm{Cu}$ at $\mathrm{pH} 5$ and the stirring rate was fixed at $100 \mathrm{rpm}$; carbamazepine concentration was $\left(5 \mathrm{mg} \mathrm{L}^{-1}\right)$, and the removal percentages were $(51,57$,
Fig. 4 Point of zero charge of $\mathrm{Fb}-\mathrm{nZVI} / \mathrm{Cu}$ nanoparticles

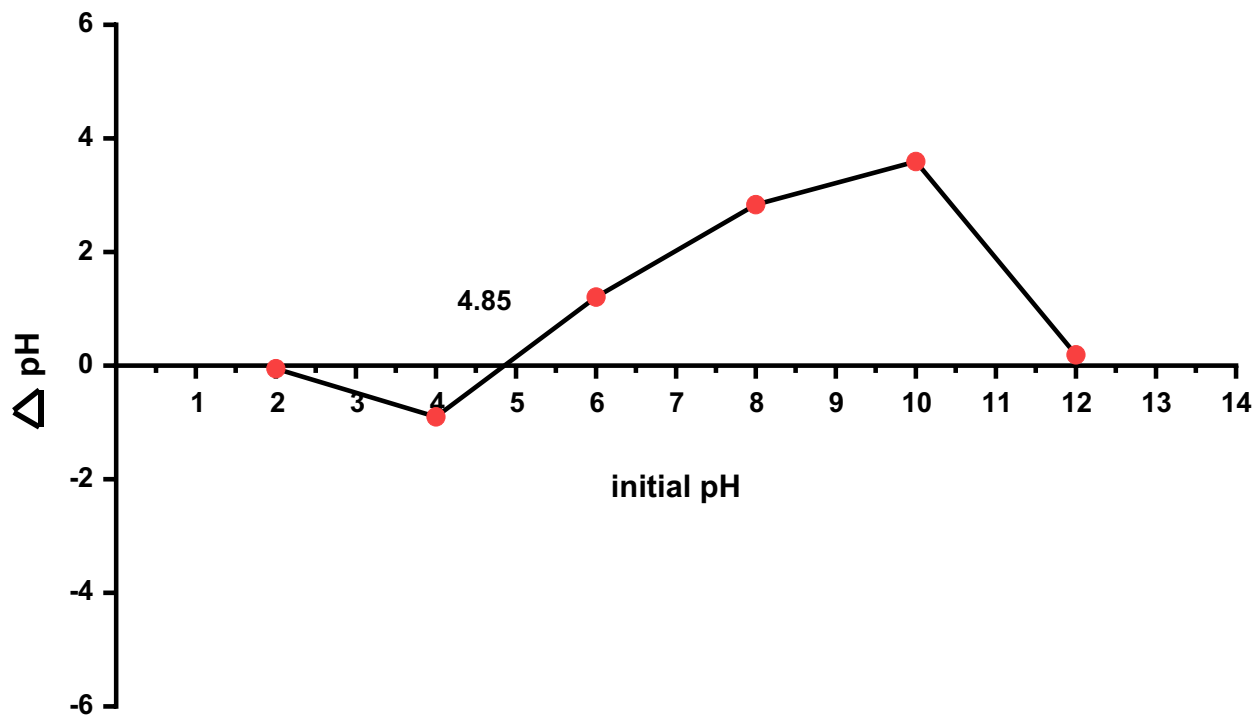




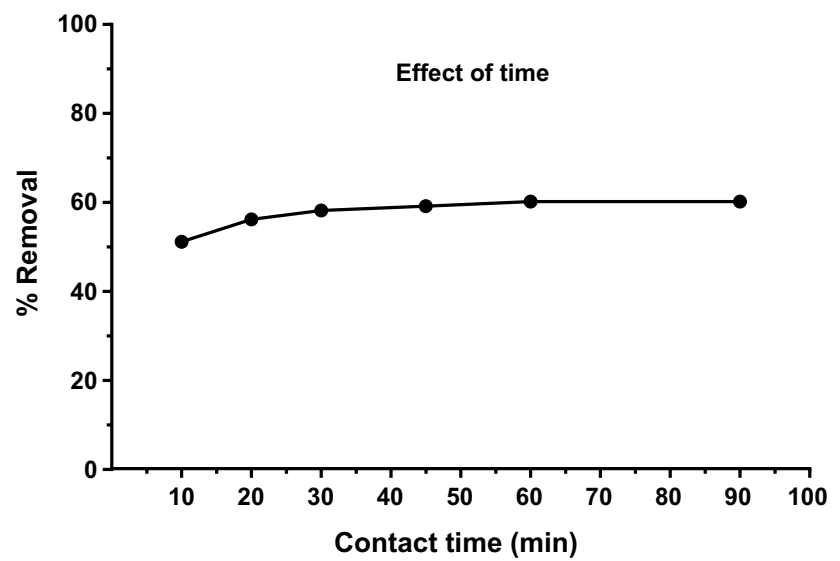

Fig. 6 Effect of contact time on carbamazepine removal
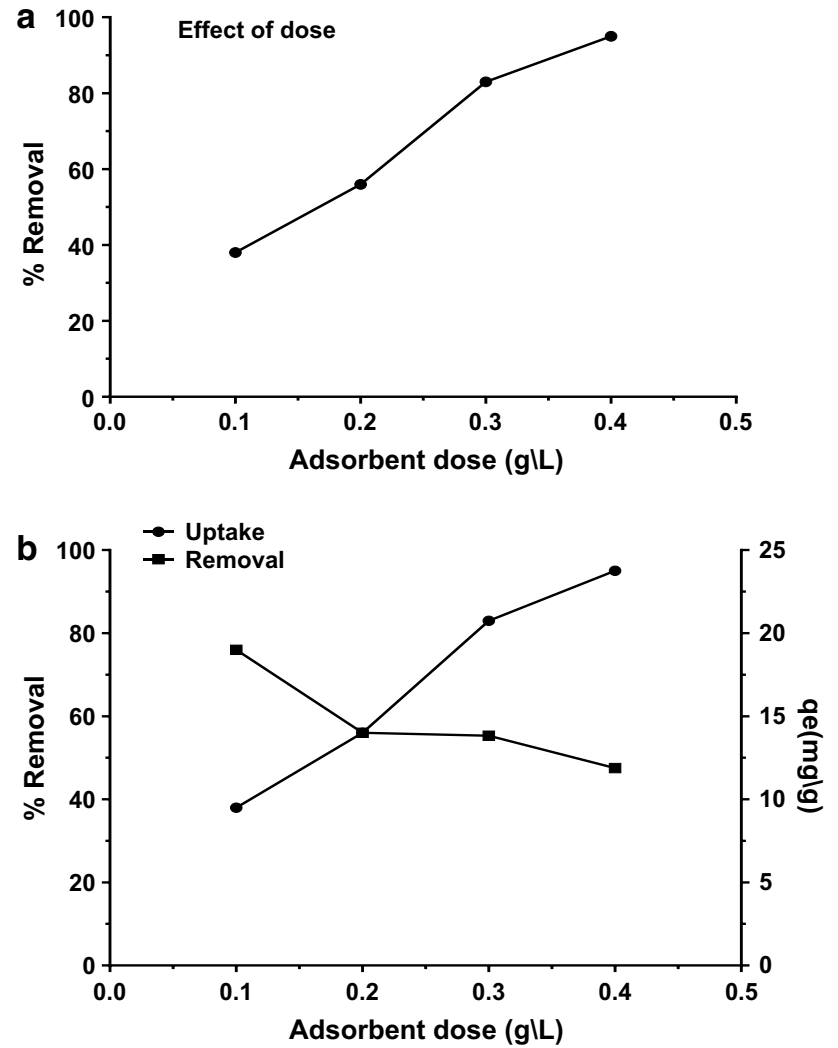

Fig. 7 a Effect of adsorbent dose on carbamazepine removal. b Optimum effective dose for carbamazepine removal

$58,59,60$, and 60\%). From the data given in Fig. 6, it is shown that increase in contact time leads to an increase in removal efficiency. Increase in time leads to an increase in the contact between the carbamazepine to a lot of free vacant sites for the adsorption of FB-nZVI/Cu.

\section{Effect of Adsorbent Dose}

Figure 7a depicts carbamazepine removal efficiency as a function of the adsorbents dose. FB-nZVI/Cu doses were varied between 0.1 and $0.4 \mathrm{~g} \mathrm{~L}^{-1}$. Other operational factors such as $\mathrm{pH}$, contact time, and stirring rate were 5, $20 \mathrm{~min}$, and $100 \mathrm{rpm}$, respectively. Carbamazepine concentration was $5 \mathrm{mg} \mathrm{L}^{-1}$ and the removal percentages were 38,56 , 83 , and 95 . The optimum adsorbent dose for carbamazepine removal was found to be about $0.2 \mathrm{~g} \mathrm{~L}^{-1}$, as shown in Fig. 7b. As expected, increase in the adsorbent dose leads to an increase in the number of vacant adsorption sites; then, the removal increased.

\section{Effect of Stirring Rate}

Figure 8 depicts carbamazepine removal efficiency by FB$\mathrm{nZVI} / \mathrm{Cu}$ as a function of stirring rate. The stirring rate was varied between 100 and $250 \mathrm{rpm}$. The other operational factors such as $\mathrm{pH}$, contact time, and adsorbents dose were 5, $20 \mathrm{~min}$ and $0.2 \mathrm{~g} \mathrm{~L}^{-1}$, respectively. Carbamazepine concentration was $5 \mathrm{mg} \mathrm{L}^{-1}$ and the removal percentages were $56,57,57,58$, and $58 \%$. The optimum stirring rate for carbamazepine removal was found to be $100 \mathrm{rpm}$. Increase in stirring rate may be enhanced the carbamazepine diffusion to the surface of the adsorbent. The increase in stirring rate from 100 to $250 \mathrm{rpm}$ has not a significant effect on the removal efficiency compared to $100 \mathrm{rpm}$.

\section{Effect of the Concentration}

The effect of carbamazepine concentration on the removal efficiency using FB-nZVI/Cu was studied at various concentrations $\left(1,3,5\right.$, and $\left.7 \mathrm{mg} \mathrm{L}^{-1}\right)$ at $\mathrm{pH} 5$, contact time $20 \mathrm{~min}$, stirring rate $100 \mathrm{rpm}$ and adsorbents dose was

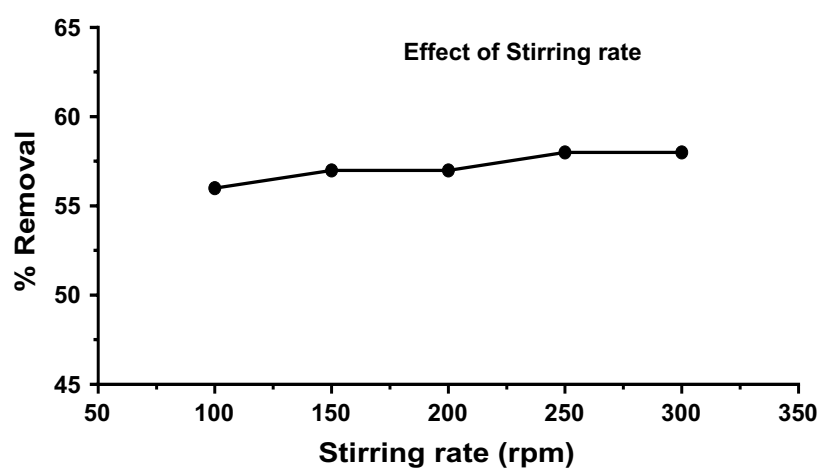

Fig. 8 Effect of stirring rate on carbamazepine removal 


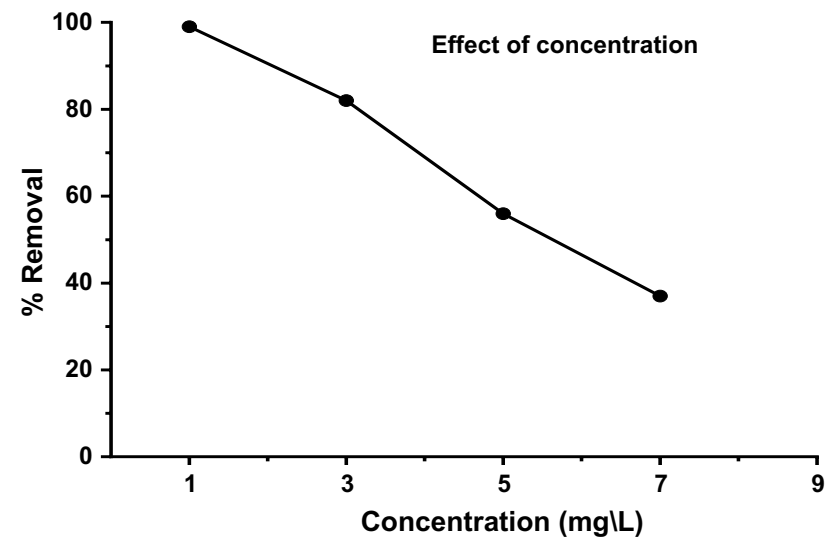

Fig. 9 Effect of concentration on carbamazepine removal
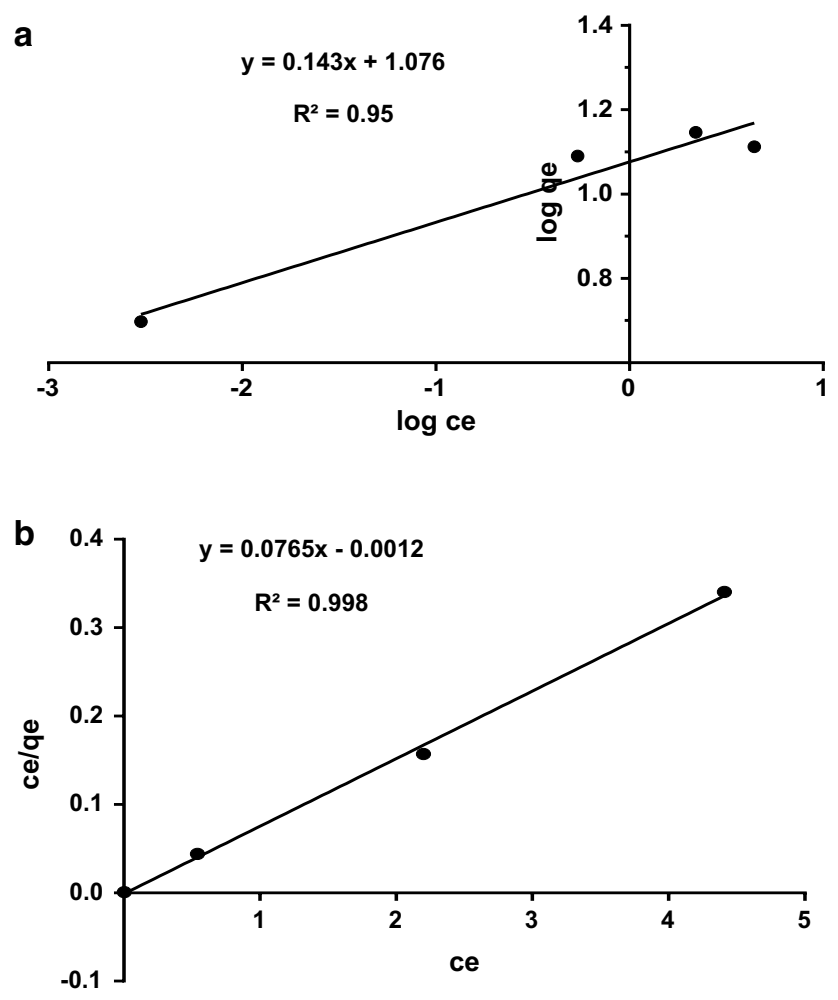

Fig. 10 a Freundlich adsorption isotherm for carbamazepine ions contributing component. b Langmuir adsorption isotherm for carbamazepine contributing component

$0.2 \mathrm{~g} \mathrm{~L}^{-1}$, and the removal percentages were 99, 82, 56, and 37\%, as shown in Fig. 9. At the beginning of adsorption operation, the removal percentage was higher because of the great number of vacant adsorption sites of FB-nZVI/ $\mathrm{Cu}$ particles, but it decreased with time progressively, due to the saturation and decrease of these sites.
Table 1 Isotherm parameters for the adsorption of carbamazepine

\begin{tabular}{llc}
\hline Isotherm name & Parameters & Values \\
\hline Freundlich & $n$ & 6.981 \\
& $R^{2}$ & 0.95 \\
Langmuir & $q_{\max }\left(\mathrm{mg} \mathrm{g}^{-1}\right)$ & 13.07 \\
& $R^{2}$ & 0.998 \\
\hline
\end{tabular}

Table 2 Variables entered/removed

\begin{tabular}{|c|c|c|c|}
\hline Model & Variables entered & Variables removed & Method \\
\hline 1 & $\begin{array}{l}\text { Concentration, dose, time, } \mathrm{pH} \text {, } \\
\text { stirring }^{\mathrm{a}}\end{array}$ & & Enter \\
\hline
\end{tabular}

Dependent variable: removal

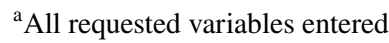

Table 3 Model summary

\begin{tabular}{lllll}
\hline Model & $R$ & $R^{2}$ & Adjusted $R^{2}$ & SE of the estimate \\
\hline 1 & $0.986^{\mathrm{a}}$ & 0.971 & 0.964 & 2.81477 \\
\hline
\end{tabular}

apredictors: (constant), concentration, dose, time, $\mathrm{pH}$, stirring

Table 4 ANOVA

\begin{tabular}{llllll}
\hline Model & Sum of squares & $d f$ & Mean square & $F$ & Sig. \\
\hline 1 Regression & 8093.749 & 5 & 1618.750 & 9.482 & $0.000^{\mathrm{a}}$ \\
Residual & 4267.735 & 25 & 170.709 & & \\
Total & $12,361.484$ & 30 & & & \\
\hline
\end{tabular}

Dependent variable: removal

aPredictors: (constant), concentration, dose, $\mathrm{pH}$, time, stirring

\section{Adsorption Isotherm Studies for Carbamazepine Removal}

The sorption capacity of the adsorbent predicted and evaluated by adsorption isotherm study. The adsorption equilibrium data obtained at different initial carbamazepine concentrations were described using Freundlich and Langmuir isotherm models, and equations are the most two common isotherm applications used for wastewater treatment, under predefined conditions of $\mathrm{pH}$, initial concentrations, adsorbent dose, contact time, and stirring rate) (Abdel-Gawad and Hossam 2018). The acceptability and suitability of the isotherm equation to the equilibrium data were based on the values of the correlation coefficients, and $R^{2}$ estimated from linear regression of the least square fit statistic on Micro Math Scientist software. Figure 10a, b represents the 
Table 5 Coefficients

\begin{tabular}{|c|c|c|c|c|c|c|}
\hline \multicolumn{2}{|c|}{ Model } & \multicolumn{2}{|c|}{ Unstandardized coefficients } & \multirow{2}{*}{$\begin{array}{l}\text { Standardized coef- } \\
\text { ficients } \\
\text { Beta }\end{array}$} & \multirow[t]{2}{*}{$t$} & \multirow[t]{2}{*}{ Sig. } \\
\hline & & $B$ & SE & & & \\
\hline \multirow[t]{6}{*}{1} & (Constant) & 73.325 & 20.904 & & 3.508 & 0.002 \\
\hline & $\mathrm{pH}$ & -3.987 & 1.608 & -0.294 & -2.479 & 0.020 \\
\hline & Time & 0.210 & 0.152 & 0.164 & 1.378 & 0.180 \\
\hline & Dose & 229.150 & 54.139 & 0.499 & 4.233 & 0.000 \\
\hline & Stirring & 0.060 & 0.051 & 0.139 & 1.165 & 0.255 \\
\hline & Concentration & -12.124 & 2.707 & -0.528 & -4.479 & 0.000 \\
\hline
\end{tabular}

Dependent variable: removal

adsorption isotherms for the four models. The adsorption data were fitted well with the Langmuir isotherm models with the highest $R^{2}$ in their categories, as shown in Table 1 . The $n$ value $>1$ from Freundlich and maximum adsorption capacity of $13.07 \mathrm{mg} \mathrm{g}^{-1}$ from Langmuir are the indication that the adsorption is favorable on the investigated adsorbent.

\section{Statistical Analysis}

The effect of the following variables on the removal process (e.g., $\mathrm{pH}$, contact time, dose, concentration, and stirring rate have been studied using the entered method, where it was found that $R^{2}=0.971$, as shown in Table 3. This means that the studied variables profane occupy more than $97 \%$ of the total of the variables affecting the removal process as that the standard error of the estimate is 2.81477 , which means that the percentage of error in this study is very low.

ANOVA program was applied and the data are given in Table 4, which showed the sum of squares and the effect of the whole model. It was observed that the $P$ value $(0.000)$, where the model is considered successful if $P$ value less than 0.05 .

The data given in Table 5 [Coefficients ${ }^{\mathrm{a}}$ ] showed the sum of squares, $P$ value, and $T$ value for each variable. From the table, it can be inferred that all variables had an effect on the removal process except (contact time and stirring rate), where the $P$ value is larger than 0.05 , where this means that it can be neglected during the removal process (Tables 2 , $3,4,5)$.

\section{Analysis of Statistical and Practical Results' Correlation}

The effect of different operating parameters was investigated using linear regression analysis using SPSS Statistics, where the obtained results support the practical results. The results showed that the effect of $\mathrm{pH}$ and concentration has a significant effect on the removal process, where the $P$ value is less than 0.005 , but the effect of the contact time and stirring rate was considered to be not significant, where the
$P$ value $(0.180$, and 0.225$)$ is more than 0.05 . By applying the $B$ values shown in Table 5, the removal equation can be deduced, whereas:

$$
\begin{aligned}
R \%= & B_{0}+B_{1} X_{1}+B_{2} X_{2}+B_{3} X_{3}+B_{4} X_{4}+B_{5} X_{5} \\
= & 73.325+(-3.987) X_{1}+(0.210) X_{2}+(229.150) X_{3} \\
& +(0.060) X_{4}+(-12.124) X_{5} .
\end{aligned}
$$

\section{Conclusions}

In this study, the green nanoscale zero-valent $\mathrm{Fe} / \mathrm{Cu}$ (FB$\mathrm{nZVFe} / \mathrm{Cu}$ ) is capable of carbamazepine removal from aqueous solution. Various operating parameters on carbamazepine removal efficiency investigated and optimized. Removal affected by the experimental conditions such as $\mathrm{pH}$, contact time, dose, stirring rate, and carbamazepine concentration. Maximum carbamazepine removal was observed at the $\mathrm{pH}$ 5. Carbamazepine removal efficiency between 99 and 37\% was achieved after using different carbamazepine concentrations $\left(1,3,5\right.$, and $\left.7 \mathrm{mg} \mathrm{L}^{-1}\right)$ with $0.2 \mathrm{~g} \mathrm{~L}^{-1}$ of FB-nZVI/ $\mathrm{Cu}$, stirring rate $100 \mathrm{rpm}$ and contact time $20 \mathrm{~min}$. When the nanoscale zero-valent iron/ $\mathrm{Cu}$ dose was increased from 0.1 to $0.4 \mathrm{mg} \mathrm{L}^{-1}$, the removal of carbamazepine increased by $57 \%\left(C_{0}=5 \mathrm{mg} \mathrm{L}^{-1}\right)$. The adsorption data were fitted well with the Langmuir isotherm model with the highest $\left(R^{2}=0.998\right)$. The FB-nZVI/Cu being eco-friendly alternative technique and can lead to success in wastewater treatment and produce high-quality treated effluent.

\section{Compliance with Ethical Standards}

Conflicts of interest The authors certify that they have no affiliations with or involvement in any organization or entity with any financial interest (such as honoraria; educational grants; participation in speakers' bureaus; membership, employment, consultancies, stock ownership, or other equity interest; and expert testimony or patent-licensing arrangements), or non-financial interest (such as personal or professional relationships, affiliations, knowledge, or beliefs) in the subject matter or materials discussed in this manuscript. The authors report the following details of affiliation or involvement in an organization or entity with a financial or non-financial interest in the subject matter or materials discussed in this manuscript. 
Open Access This article is distributed under the terms of the Creative Commons Attribution 4.0 International License (http://creativeco mmons.org/licenses/by/4.0/), which permits unrestricted use, distribution, and reproduction in any medium, provided you give appropriate credit to the original author(s) and the source, provide a link to the Creative Commons license, and indicate if changes were made.

\section{References}

Abdel-Gawad SA, Abd El-Aziz HM (2019a) Removal of ethinylestradiol by adsorption process from aqueous solutions using entrapped activated carbon in alginate biopolymer: isotherm and statistical studies. Appl Water Sci 9:75

Abdel-Gawad SA, Abd El-Aziz HM (2019b) Removal of pharmaceuticals from aqueous medium using entrapped activated carbon in alginate. Air Soil Water Res 12:1178622119848761

Abdel-Gawad SAA-A, Hossam M (2018) Effective removal of chemical oxygen demand and phosphates from aqueous medium using entrapped activated carbon in alginate. MOJ Biol Med 3:227-236

Abdel-Gawad SA, Baraka AM, El-Shafei MM, Mahmoud AS (2016) Effects of nano zero valent iron and entrapped nano zero valent iron in alginate polymer on poly aromatic hydrocarbons removal. J Environ Biotechnol Res 5:18-28

Al-Qahtani KM (2017) Cadmium removal from aqueous solution by green synthesis zero valent silver nanoparticles with Benjamina leaves extract. Egypt J Aquat Res 43:269-274

Baghdadi M, Ghaffari E, Aminzadeh B (2016) Removal of carbamazepine from municipal wastewater effluent using optimally synthesized magnetic activated carbon: adsorption and sedimentation kinetic studies. J Environ Chem Eng 4:3309-3321

Chtourou M, Mallek M, Dalmau M, Mamo J, Santos-Clotas E, Salah AB, Walha K, Salvadó V, Monclús H (2018) Triclosan, carbamazepine and caffeine removal by activated sludge system focusing on membrane bioreactor. Process Saf Environ Prot 118:1-9

Cunningham VL, Perino C, Vincent J, Hartmann A, Bechter R (2010) Human health risk assessment of carbamazepine in surface waters of North America and Europe. Regul Toxicol Pharmacol $56: 343-351$

Danish M, Gu X, Lu S, Ahmad A, Naqvi M, Farooq U, Zhang X, Fu X, Miao Z, Xue Y (2017) Efficient transformation of trichloroethylene activated through sodium percarbonate using heterogeneous zeolite supported nano zero valent iron-copper bimetallic composite. Chem Eng J 308:396-407

Devatha C, Thalla AK, Katte SY (2016) Green synthesis of iron nanoparticles using different leaf extracts for treatment of domestic waste water. J Clean Prod 139:1425-1435

Domínguez JNR, González T, Palo P, Sánchez-Martín J (2010) Electrochemical advanced oxidation of carbamazepine on boron-doped diamond anodes. Influence of operating variables. Ind Eng Chem Res 49:8353-8359

Dong C, Cao C, Zhang X, Zhan Y, Wang X, Yang X, Zhou K, Xiao X, Yuan B (2017) Wolfberry fruit (Lycium barbarum) extract mediated novel route for the green synthesis of silver nanoparticles. Optik Int J Light Electron Opt 130:162-170

El-Shafei M, Mahmoud A, Mostafa M, Peters R (2016) Effects of entrapped nZVI in alginate polymer on BTEX removal. In: AIChE annual meeting, pp 13-18

Farag RS, Elshfai MM, Mahmoud AS (2018a) Adsorption and kinetic studies using nano zero valent iron (nZVI) in the removal of chemical oxygen demand from aqueous solution with response surface methodology and artificial neural network approach. J Environ Biotechnol Res 7:12-22

Farag RS, Mahmoud AS, Mostafa MK, Peters RW (2018) Green synthesis of nano iron carbide: preparation, characterization and application for removal of phosphate from aqueous solutions. In: Proceeding 2018 annual AIChE Meeting, Pittsburgh, PA, (October 28-November 2)

Fathima JB, Pugazhendhi A, Oves M, Venis R (2018) Synthesis of eco-friendly copper nanoparticles for augmentation of catalytic degradation of organic dyes. J Mol Liq 260:1-8

Freundlich H (1906) Over the adsorption in solution. J Phys Chem 57:e470

García-Gómez C, Drogui P, Zaviska F, Seyhi B, Gortáres-Moroyoqui P, Buelna G, Neira-Sáenz C, Estrada-Alvarado M, Ulloa-Mercado R (2014) Experimental design methodology applied to electrochemical oxidation of carbamazepine using $\mathrm{Ti} / \mathrm{PbO}_{2}$ and $\mathrm{Ti} / \mathrm{BDD}$ electrodes. J Electroanal Chem 732:1-10

Gurung K, Ncibi MC, Shestakova M, Sillanpää M (2018) Removal of carbamazepine from MBR effluent by electrochemical oxidation (EO) using a Ti/ $\mathrm{Ta}_{2} \mathrm{O}_{5}-\mathrm{SnO}_{2}$ electrode. Appl Catal B 221:329-338

Khani R, Roostaei B, Bagherzade G, Moudi M (2018) Green synthesis of copper nanoparticles by fruit extract of Ziziphus spinachristi (L.) Willd.: application for adsorption of triphenylmethane dye and antibacterial assay. J Mol Liq 255:541-549

Langmuir I (1918) The adsorption of gases on plane surfaces of glass, mica and platinum. J Am Chem Soc 40:1361-1403

Li X, de Toledo RA, Wang S, Shim H (2015) Removal of carbamazepine and naproxen by immobilized Phanerochaete chrysosporium under non-sterile condition. New Biotechnol 32:282-289

Liu Z, Zhao C, Wang P, Zheng H, Sun Y, Dionysiou DD (2018) Removal of carbamazepine in water by electro-activated carbon fiber-peroxydisulfate: comparison, optimization, recycle, and mechanism study. Chem Eng J 343:28-36

Mahmoud AS, El-Tayieb MM, Ahmed NAS, Mostafa AM (2018a) Algorithms and statistics for municipal wastewater treatment using nano zero valent iron (nZVI). J Environ Biotechnol Res $7: 30-44$

Mahmoud AS, Mostafa MK, Abdel-Gawad SA (2018b) Artificial intelligence for the removal of benzene, toluene, ethyl benzene and xylene (BTEX) from aqueous solutions using iron nanoparticles. Water Sci Technol Water Supply 18:1650-1663

Mahmoud AS, Ismail A, Mostafa MK, Mahmoud M, Ali W, Shawky AM (2019a) Isotherm and kinetic studies for heptachlor removal from aqueous solution using $\mathrm{Fe} / \mathrm{Cu}$ nanoparticles, artificial intelligence, and regression analysis. Sep Sci Technol 54:1-13

Mahmoud AS, Mostafa MK, Nasr M (2019b) Regression model, artificial intelligence, and cost estimation for phosphate adsorption using encapsulated nanoscale zero-valent iron. Sep Sci Technol 54:13-26

Misra T, Mitra S, Sen S (2018) Adsorption studies of carbamazepine by green-synthesized magnetic nanosorbents. Nanotechnol Environ Eng 3:11

Nielsen L, Zhang P, Bandosz TJ (2015) Adsorption of carbamazepine on sludge/fish waste derived adsorbents: effect of surface chemistry and texture. Chem Eng J 267:170-181

Puente C, Gómez I, Kharisov B, López I (2019) Selective colorimetric sensing of $\mathrm{Zn}$ (II) ions using green-synthesized silver nanoparticles: ficus benjamina extract as reducing and stabilizing agent. Mater Res Bull 112:1-8

Qin N, Zhang Y, Zhou H, Geng Z, Liu G, Zhang Y, Zhao H, Wang G (2016) Enhanced removal of trace $\mathrm{Cr}(\mathrm{VI})$ from neutral and alkaline aqueous solution by FeCo bimetallic nanoparticles. J Colloid Interface Sci 472:8-15

Rajendran K, Sen S (2018) Adsorptive removal of carbamazepine using biosynthesized hematite nanoparticles. Environ Nanotechnol Monit Manag 9:122-127

Samara M, Nasser A, Mingelgrin U (2016) Mechanochemical removal of carbamazepine. Chemosphere 160:266-272 
Selvan DA, Mahendiran D, Kumar RS, Rahiman AK (2018) Garlic, green tea and turmeric extracts-mediated green synthesis of silver nanoparticles: phytochemical, antioxidant and in vitro cytotoxicity studies. J Photochem Photobiol B 180:243-252

Sepúlveda P, Rubio MA, Baltazar SE, Rojas-Nunez J, Llamazares JS, Garcia AG, Arancibia-Miranda N (2018) As (V) removal capacity of $\mathrm{FeCu}$ bimetallic nanoparticles in aqueous solutions: the influence of $\mathrm{Cu}$ content and morphologic changes in bimetallic nanoparticles. J Colloid Interface Sci 524:177-187

Shan D, Deng S, Zhao T, Wang B, Wang Y, Huang J, Yu G, Winglee J, Wiesner MR (2016) Preparation of ultrafine magnetic biochar and activated carbon for pharmaceutical adsorption and subsequent degradation by ball milling. J Hazard Mater 305:156-163

Soliemanzadeh A, Fekri M (2017) The application of green tea extract to prepare bentonite-supported nanoscale zero-valent iron and its performance on removal of $\mathrm{Cr}(\mathrm{VI})$ : effect of relative parameters and soil experiments. Microporous Mesoporous Mater 239:60-69

To M-H, Hadi P, Hui C-W, Lin CSK, McKay G (2017) Mechanistic study of atenolol, acebutolol and carbamazepine adsorption on waste biomass derived activated carbon. J Mol Liq 241:386-398

Wu S-J, Liou T-H, Mi F-L (2009) Synthesis of zero-valent copperchitosan nanocomposites and their application for treatment of hexavalent chromium. Biores Technol 100:4348-4353

Mahmoud AS, SaryEl-deen RA, Mostafa MK, Peters RW Artificial intelligence for organochlorine pesticides removal from aqueous solutions using entrapped nZVI in alginate biopolymer
Mostafa MK, Mahmoud AS, SaryEl-deen RA, Peters RW Application of entrapped nano zero valent iron into cellulose acetate membranes for domestic wastewater treatment

SaryEl-deen RA, Mahmoud AS, Mahmoud M, Mostafa MK, Peters RW (2017) Adsorption and kinetic studies of using entrapped sewage sludge ash in the removal of chemical oxygen demand from domestic wastewater, with artificial intelligence approach. Annual AIChE meeting, 2017

Yang B, Kookana RS, Williams M, Du J, Doan H, Kumar A (2016) Removal of carbamazepine in aqueous solutions through solar photolysis of free available chlorine. Water Res 100:413-420

Zhang J, Guo J, Wu Y, Lan Y, Li Y (2017) Efficient activation of ozone by zero-valent copper for the degradation of aniline in aqueous solution. J Taiwan Inst Chem Eng 81:335-342

Zhu S, Liu Y-G, Liu S-B, Zeng G-M, Jiang L-H, Tan X-F, Zhou L, Zeng W, Li T-T, Yang C-P (2017) Adsorption of emerging contaminant metformin using graphene oxide. Chemosphere 179:20-28

Zhu F, Ma S, Liu T, Deng X (2018) Green synthesis of nano zerovalent iron/Cu by green tea to remove hexavalent chromium from groundwater. J Clean Prod 174:184-190 